\title{
Regional innovation: State of the art in the Észak-alföld region
}

\author{
Ágnes Barbara Berde \\ INNOVA Észak-Alföld Regional Development and Innovation Agency Nonprofit Ltd., \\ Debrecen, 4031, Kürtös u. 4. \\ agnes.berde@eszak-alfold.hu
}

Keywords: regional innovation, innovation policy, regional innovation system, innovation performance, Észak-Alföld region

\section{SUMMARY}

\begin{abstract}
Innovation and innovation performance is gaining increasing importance in European policy, as the targets determined by the Lisbon priorities related to innovation seem to be still far away from the reality in some European countries and at EU level as well. Although the economic crisis determined the priorities of economic development and made it more complicated to dedicate more budget of Research and Development, one of the five ambitious objectives of the EU's growth strategy for the coming decade: Europe 2020: A strategy for smart, sustainable and inclusive growth is still focusing on innovation. As the Lisbon Strategy determined the paths for national targets in the given areas, Europe 2020 will be adopted as well by the Member States.
\end{abstract}

In this context, the current work would like to give a short overview how Lisbon Strategy effected the national and regional innovation system in Hungary and will analyze its impact on Észak-Alföld's region Research, Development and Innovation performance in the recent years and the transition of regional innovation governance system.

\section{INTRODUCTION}

\subsection{THE EUROPEAN CONTEXT}

The European Council in March 2000 in Lisbon agreed on a new strategic goal for the Union for the upcoming decade in order to strengthen employment, economic reform and social cohesion as part of a knowledge-based economy (EC, 2000). The aim of the document by setting up its objective until 2010 was to close the gap between Europe and its main global competitors, the United States and Japan: "to become the most competitive and dynamic knowledge-based economy in the world capable of sustainable economic growth with more and better jobs and greater social cohesion" (EC, 2000).

Since 2000, innovation is considered to be one of the most important driving factors behind sustainable economic development; therefore the Commission was urging to build an innovation oriented strategy around the concept of a European Research Area (ERA). Regarding to the Council conclusions Europe suffered from three weaknesses from competitiveness point of view: insufficient funding, lack of an environment to stimulate research and exploit results, and the fragmented nature of activities and the dispersal of resources. To overcome these problems the Commission sought to coordinate research and innovation policies taking into account all relevant aspects of EU and national policies. The concept was to combine the development of a European research policy with the creation of an 'internal market' for research.

In addition regions emerged as strategic players in developing a well-functioning European Research Area. "Research policy territorialization - according to Commission's Communication - addresses two main issues: first, increasing regional awareness of national research and innovation policies and tuning them towards the socioeconomic needs of the regions; and second, directing these policies to build research and innovation capacity in the regions, enhancing their ability to act as drivers for economic and technological development". (EC, 2001)

In order to achieve the above mentioned goal the following priorities had been developed:

- Establishing research and innovation strategies to develop material and human resources

- Fostering partnerships between the public and the private sector

- Promoting an environment conducive to research and innovation, through the introduction of accompanying legal, financial and fiscal conditions

- $\quad$ Stimulating experience exchange with other successful regions in specific fields.

- Contributing actively to an integrated strategy for sustainable development

A long list of measurable sub-goals had been set up in the Lisbon Strategy as well, like the objectives that each member state shall increase R\&D expenditures to three percent of GDP, of which two-thirds should come from the private sector, and the employment rate to 70 percent by 2010 . These goals have been proved too ambitious at European level and especially for some Newly Acceded Countries. 


\subsection{THE HUNGARIAN CONTEXT}

In 2002-2003 the Hungarian innovation policy was renewed and adapted the goals of Lisbon Strategy within its framework, therefore first it set up the legal framework for the Hungarian innovation system, dedicated a reluctant financing mechanism to it and created a governance system. In Hungary due to the centralized economy and public administration system, the RDI policy in the regions was regulated on national level, although there was a light tendency to give more entitlement to the regions.

The most important laws on national level determining the Hungarian national and regional innovation system are:

- Research and Technological Innovation Fund: Act XC of 2003, approved by the Hungarian Parliament established the Research and Technological Innovation Fund. The Act provided stable and reliable financing for RTDI activities. The Fund is financed by mandatory contributions of all companies registered in Hungary, matched yearly by the government budget. The so-called innovation contribution, based of the (adjusted) net turnover, for medium size and large companies grew from $0.2 \%$ in 2004 to $0.3 \%$ by 2006. Microenterprises and small-size enterprises were exempt from paying a contribution. It was also a legal requirement that resources of the Fund have to be spent through competitive calls, and at least $\mathbf{2 5 \%}$ should go for regional innovation purposes.

- Act CXXXIV 2004 Innovation Law: The main purposes of the Law were to promote sustainable development of the Hungarian economy by improving the conditions to achieve and exploit R\&D results and technological innovation; to enhance the competitiveness of enterprises and facilitate the efficient exploitation of regional R\&D and innovation possibilities; to create jobs with high value added activities; to improve the professional skills of researchers and promote the appreciation of their activities; and to contribute to the dissemination of advanced technologies to improve defense capabilities of the country.

In 2003-2004 the following weaknesses were featuring the innovation system in Hungary:

- Regarding the number of inhabitants and the number of university student the overwhelming role of Budapest can be observed, that can mean the gap between the capital and the Hungarian regions will further increase from the point of competitiveness

- The results of the economic growth are derived not from the high-value added innovation performance but from the short-term impacts of the foreign investments.

- The lack of entrepreneur promotion organization, the lack of innovation intermediaries can be observed in the regions. Weak technology and knowledge transfer practices in the regions are hindering that scientific results will turn into product and service innovation in the given regions.

- There were no clustering between research entities and companies and no networking amongst the actors.

- Regional economic development, creation of jobs and innovation capacity of the SMEs are really poor in the regions.

- There is only a few new technology intensive company and even less spin-off companies at the universities relying on scientific results.

From this point of view, the strengthening of regional innovation systems was seen as a crucial point in the creation of the innovation system. As mentioned earlier the Act on Research and Technological Innovation Fund created the legal, institutional and financial framework for that by dedicating $25 \%$ of the yearly budget to regional innovation purposes. The basis of the regional reallocation was based on the long term strategies and goals of Hungarian regional development policy determined by the Act on Regional Development and Physical Planning of 1996 creating a new sub-national governmental system. The Act on Regional Development thus created new NUTS II regions (EU programming regions) as well as NUTS IV level so-called "statistical microregions", while the former NUTS III level counties were retained. Simultaneously, to facilitate multi-level coordination a National Regional Development Council was established.

\section{2. ÉSZAK-ALFÖLD REGION}

In 2004, in line with the Innovation Act different measures were adopted to decrease government involvement in the functioning of regions while strengthening the role of professional associations and NGOs at regional level, therefore this current paper is summarizing the effects of these measures on the regional innovation system of Észak-Alföld.

Following Braczyk et al (1998) two dimensions of innovation system can be differentiated: the governance dimension comprising public policy, institutions and knowledge infrastructure and the business incubation dimension meaning the level of investment in $R \& D$, the type of firms and their level of linkages. In the business innovation dimension, three categories of regional innovation systems can be distinguished: the localist, dominated by large firms with a few major public innovation or R\&D sources; an interactive RIS is when the balance between large and small firms is ensured and finally the globalized is dominated by global companies. Based on these characteristics Észak-Alföld region can be featured somewhere between a localist and an interactive regional innovation system, whereas there is only a limited number of larger firms influencing largely 
the $R \& D$ performance of the region, like pharmaceutical companies, but there is a tendency to shift more towards the interactive system. Cooke (2004) distinguished 3 categories on the governance dimension by the regional innovation systems: grassroots, network and dirigiste RIS. shows the typology of regional innovation systems and based on these characteristics Észak-Alföld's governance system can be featured as a dirigiste system.

Typology of regional innovation systems and key action impulses

\begin{tabular}{|l|l|l|l|}
\hline RIS characteristics & Grassroots & Network & Dirigiste \\
\hline Initiation & Local & Multilevel & Central \\
\hline Funding & Diffused & Guided & Determined \\
\hline Research & Applied & Mixed & Basic \\
\hline Coordination & Low & High & High \\
\hline Specialization & Weak & Flexible & Strong \\
\hline
\end{tabular}

Source: Cooke, 1992

A dirigiste system is animated mainly from outside and above the region; innovation occurs as a product of a central governmental policy, funding is centrally determined with decentralized units located in the region. Initiation and inspiration are centrally influenced and funding is program-based. Although the need to decentralise funds, administration and to strengthen the governance was expressed in the measures accomplished between 2005 and nowadays, the level of governance remained at dirigiste level (Table 1).

In the period of 2004 - 2006 the main source of RDI financing at regional level were mostly the regional dimension of the Research and Technological Innovation Fund and the available resources of the Structural funds were negligible. In the current programming period the available range of sources were completed with the different operational programs of the Structural Funds, especially with the Regional Operational Program available in each region. Graph 1 shows the structure if the R\&D\&I financing system and its priorities in the period of 2007-2010 at national level, that could have affected the regional innovation performance.

Graph 1.: R\&D\&I Sources of funding available in Észak-Alföld region between 2007-2010

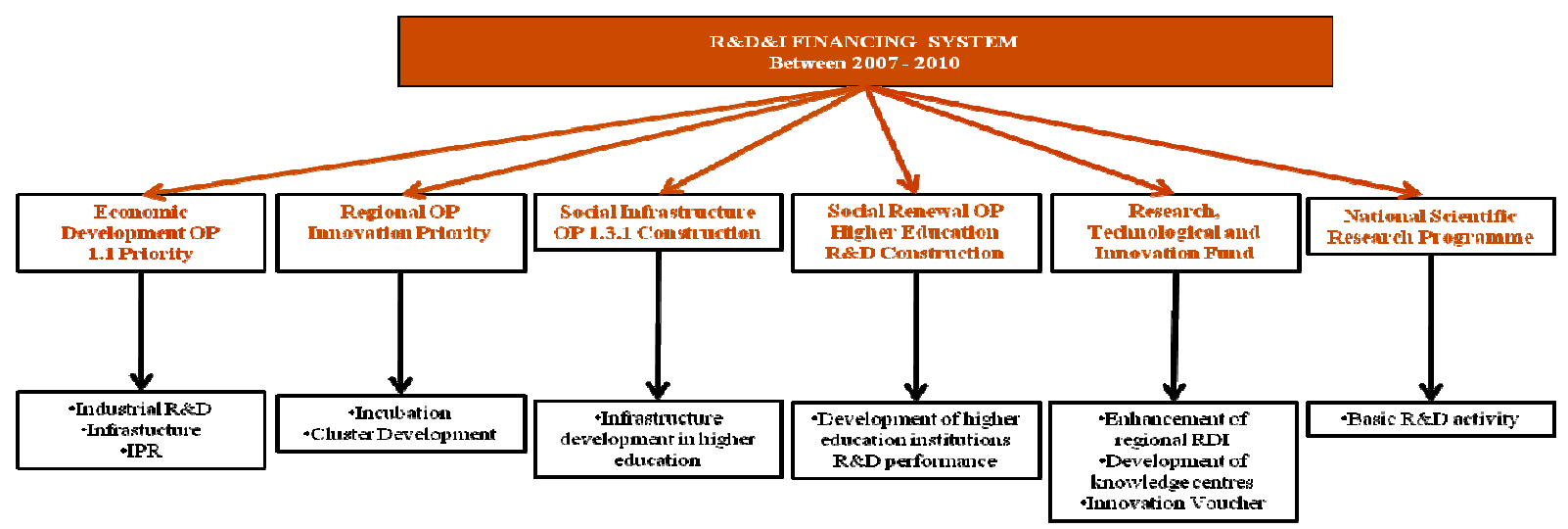

Source: Own resource

The strategic planning of the regional operational program and of the regional dimension of Research, Technological and Innovation Fund was dedicated to regional actors. Although a partial decentralization had been accomplished, the preparation and the planning of the programs were prepared at regional level by the regional actors like regional development agency or the regional innovation agency; still final decisions were brought at national level by the different managing authorities.

Regarding the type of research funded, it can be stated that it is funding more a mixed approach: basic and applied research and on that level a shift can be observed toward a network system. So to sum up Észak-Alföld's regional innovation system is localist on business innovation dimension and is a dirigiste on governance level.

Innovation is the commercialization of a new knowledge (Cooke, 2006). Unless the knowledge is generated in a large firm, it is likely that the process of knowledge exploitation has to be supported by policy instruments and intermediary agencies. In Észak-Alföld region several intermediary bodies have been established in the recent years deriving from different measures, like regional innovation agency, technology transfer office, incubators, industrial parks, cluster organizations. These bodies have been launched mostly since 2005 and most of them have been financed from different programs. Therefore these organizations had recently found their 
positions in the regional innovation system and could determine and distinguish there innovation support service, although as they are program funded there is a certain uncertainty in their continuous financing.

Regional innovation performance can be numerated by a few indicators like R\&D intensity, number of patent applications and number of RCD personnel, etc. In 2002-2003, the over-centralized role of Budapest could be observed and there was a big need to decrease the gap between the regions and the capital. Taking a closer look at Eurostat data some minor changes can be observed in the recent years. There has been a slight shift towards the regions from the point of R\&D expenditure in percentage of GDP and in Észak-Alföld region a definite increase can be observed in Graph 2 between 2002 and 2007. Since 2002 R\&D expenditure increased from 0.65 to 0.85 and based on Hungarian Statistical Information, this figure is approx. 1 percent today.

Graph 2.: Total intramural R\&D expenditure (GERD) in Hungary 2002-2007

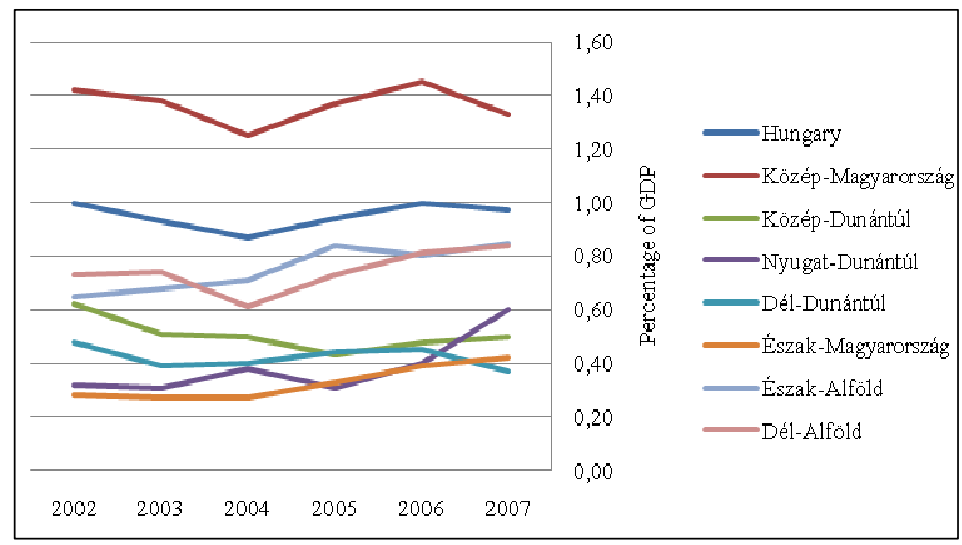

Source: Eurosta

There is an impact of the different sources on Total intramural R\&D expenditure (GERD) by sectors of performance: business enterprise sector as well. The percentage had been increased from 0.23 percent from 2002 to 0.42 in 2007, furthermore an increase of $22 \%$ can be observed in the number of R\&D personnel and in the number of researchers in Észak-Alföld region.

What can be stated as a weakness, that there has been no increase in the number of patent applications to the EPO; there has even been a modest decrease. This means that the knowledge transfer and the exploitation of research results needs still a strong support and further development.

\section{CONCLUSION}

There have been a lot of changes in the regional innovation system in Észak-Alföld region. In 2004, in line with the Innovation Act different measures were adopted to decrease government involvement in the functioning of regions while strengthening the role of professional associations, of intermediate bodies, strengthening the linkages between the business sector and research organizations, clustering had been supported as well from mainstream programs, incubators, industrial parks had been set up. Even if all these measures had been successfully accomplished, weak technology and knowledge transfer are still hindering that those scientific results will turn into product and service innovation in Észak-Alföld region. Further continuation of strengthening the regional dimension of innovation is still crucial in order to avoid the further competitive dropoff from the capital and from other European regions.

\section{REFERENCES}

Braczyk, H., P. Cooke and M. Heidenreich (eds.) (1998), Regional Innovation Systems, London: UCL Press

Cooke, P. (1992), "Regional Innovation Systems: Competitive Regulation in the New Europe”, Geoforum, 23, pp. 365-382.

Cooke, P., M. Heidenreich and H.J. Braczyk (eds.) (2004), Regional Innovation Systems, 2nd edition (London: Routledge).

Cooke, P. (2006): Regional Innovation systems as public goods, United Nations Industrial Development Organization, Vienna International Centre

European Commission (2000) Presidency conclusions of the Lisbon European council, March 23/24., Brussels: Commission of the European Communities.

European Commission (2001) The regional dimension of the European research area. Brussels: Commission of the European Communities. http://www.iglortd.org/Content/ERA/Com01_549en.pdf 
European Commission 2010: Europe 2020: A strategy for smart, sustainable and inclusive growth, http://eurlex.europa.eu/LexUriServ/LexUriServ.do?uri=COM:2010:2020:FIN:EN:PDF, Luxembourg : Office for Official Publications of the European Communities 